\title{
Pore Size Dependent Molecular Adsorption of Cationic Dye in Biomass Derived Hierarchically Porous Carbon
}

\author{
Long Chen, ${ }^{1}$ Tuo Ji, ${ }^{1}$ Liwen $\mathrm{Mu},{ }^{1,2}$ Yijun Shi, ${ }^{2}$ Huaiyuan $\mathrm{Wang}^{3}$ and Jiahua $\mathrm{Zhu}{ }^{1}$ * \\ ${ }^{1}$ Intelligent Composites Laboratory, Department of Chemical and Biomolecular Engineering, \\ The University of Akron, Akron, OH 44325 USA \\ ${ }^{2}$ Division of Machine Elements, Luleå University of Technology, Luleå, 97187, Sweden \\ ${ }^{3}$ College of Chemistry and Chemical Engineering, Northeast Petroleum University, Daqing \\ 163318, P. R. China \\ Corresponding author: Jiahua Zhu. Email: jzhu1@uakron.edu
}


Abstract: Hierarchically porous carbon adsorbents were successfully fabricated from different biomass resources (soft wood, hard wood, bamboo and cotton) by a facile two-step process, i.e. carbonization in nitrogen and thermal oxidation in air. Without involving any toxic/corrosive chemicals, large surface area of up to $890 \mathrm{~m}^{2} / \mathrm{g}$ was achieved, which is comparable to commercial activated carbon. The porous carbons with various surface area and pore size were used as adsorbents to investigate the pore size dependent adsorption phenomenon. Based on the density functional theory, effective (E-SSA) and ineffective surface area (InE-SSA) was calculated considering the geometry of used probing adsorbate. It was demonstrated that the adsorption capacity strongly depends on E-SSA instead of total surface area. Moreover, a regression model was developed to quantify the adsorption capacities contributed from E-SSA and InE-SSA, respectively. The applicability of this model has been verified by satisfactory prediction results on porous carbons prepared in this work as well as commercial activated carbon. Revealing the pore size dependent adsorption behavior in these biomass derived porous carbon adsorbents will help to design more effective materials (either from biomass or other carbon resources) targeting to specific adsorption applications.

Keywords: Biomass, porous carbon, adsorption model, effective surface area, methylene blue 


\section{Introduction}

Porous materials are of great interest due to their large surface area and tunable pore structure and have found wide applications in various fields such as ion exchange (Kusakabe et al., 1998), adsorption (Kyriakopoulos and Doulia, 2006; Liu et al., 2014; Meng et al., 2015; Zhao

et al., 2015), energy production/storage (Chen et al., 2017; Dutta et al., 2014; Kyriakopoulos et al., 2016) and catalysis (Ji et al., 2016; Ji et al., 2015; Liu et al., 2010). The International Union of Pure and Applied Chemistry categorized pores into micropores $(<2 \mathrm{~nm})$, mesopores $(2-50 \mathrm{~nm})$ and macropores (>50 $\mathrm{nm}$ ) according to their pore size (Sing, 1982).

Porous materials can be fabricated by different techniques, such as physical/chemical activation (Alabadi et al., 2015; Anoop Krishnan et al., 2011; Williams and Reed, 2006), phase separation (Nakanishi and Tanaka, 2007), template method (Lee et al., 2006; Tang et al., 2015), etc. Activation is a process that converts carbonaceous source materials such as coconut husk (Babel and Kurniawan, 2004; Hasany and Ahmad, 2006), wood (Acharya et al., 2009; Wang et al., 2009) and coal (Ahmadpour and Do, 1996; Chingombe et al., 2005) into microporous materials by using activating agents. Depending on the nature of activating agents, the process can be classified as physical (Ahmadpour and Do, 1996; Rodríguez-Reinoso and Molina-Sabio, 1992) or chemical activation (Chen et al., 2015a; Diao et al., 2002; Tsai et al., 1998). Activated carbon can achieve surface area ranging from 500 to $3000 \mathrm{~m}^{2} / \mathrm{g}$ with major micropores and nonuniform pore size distribution. As for template method, the monomers or polymer precursors are firstly impregnated/infiltrated into the pores of the template, after which, cross-linking and carbonization processes are carried out in sequence. After removing template, the monomer or polymer precursor becomes the continuous carbon framework and the space pre-occupied by the template is transferred into pores in the products (Lee et al., 2000; Qiang et al., 2014). The 
porous carbon produced from template method features uniform pore size. For both methods, either high energy consumption, complicated process, or toxic/corrosive chemicals are required, which is undesirable facing the energy and environmental challenges nowadays.

Taking advantage of rich-carbon nature, converting lignocellulosic biomass (raw resources such as wood, cotton or treated resources including cellulose, lignin, tannin and starch) into porous carbon seems a promising approach. For example, wood biomass has been processed into shape controlled hierarchical porous carbon by flash heating method (Kurosaki et al., 2008). In recent years, researchers have successfully fabricated porous carbon materials from different biomass resources such as winter melon (Li et al., 2014), shiitake mushroom (Cheng et al., 2015), banana peel (Lv et al., 2012), bamboo (Hameed et al., 2007) etc. More than that, our previous work demonstrated a facile two-step process to produce high surface area porous carbon from softwood by selectively removing lignin without using any toxic chemicals (Chen et al., 2015b). It is worthwhile to find out whether this method can be applied to produce high surface area porous carbon from different biomass resources.

Adsorption is a surface-based process that targeted atoms, ions or molecules are adhered to adsorbent surface. Porous materials with high surface area are required to achieve large adsorption capacity. However, adsorbents with large surface area sometimes give poor adsorption capacity (Chen et al., 2015a). In fact, besides the surface area, pore size distribution and size of the adsorbate molecule also affect the adsorption capacity. In previous studies, researchers related and compared the adsorption capacity directly with total surface area regardless of their pore size distribution, adsorbent size, etc., which fails to interpret the adsorption phenomenon precisely (Chen et al., 2015a). Some researchers mentioned the concept of "effective surface area" in adsorption, however, the exact definition of "effective surface area" 
was not clearly defined (Malik, 2003; Wan et al., 2015; Zare et al., 2015). Until now, rare work has been reported to correlate the adsorption capacity with effective specific surface area, pore size distribution and adsorbate molecule size. Not even to mention the attempt of constructing a model to quantify the adsorption contributed by effective and ineffective surface area. A clearly defined model will enable systematic analysis and prediction of adsorption capacity and can even help to design materials with desirable properties towards various adsorption applications.

In this work, hierarchically porous carbons were fabricated from different biomass resources, spruce-pine-fir (softwood), maple (hardwood), bamboo and cotton, by using a facile two-step (carbonization and thermal oxidation) method. The surface area and pore size can be controlled by simply changing the oxidation temperature and duration. Methylene blue was used as probing molecule to study the pore size dependent adsorption phenomenon relating the total surface area and effective surface area of these porous carbon materials. Moreover, a simple model that quantifies the adsorption capacity contribution from effective and ineffective surface area was proposed and verified. The relationship among adsorption capacity, effective specific surface area and adsorbate molecular size was analyzed in both macroscale and molecular level.

\section{Materials and methods}

\subsection{Materials}

Spruce-pine-fir (SPF), maple was purchased from Home Depot, bamboo skewers were purchased from Dave's supermarket, and cotton was obtained from commercially available Tshirt made of $100 \%$ cotton. Methylene blue (MB) was purchased from Fisher Scientific. Commercial active carbon (AC) was provided by Cabot Corporation (HDB M-1951). All chemicals were used as received without further treatment. Deionized water (Millipore) was used in all the experiment. 


\subsection{Synthesis of porous carbon}

Biomass derived porous carbon was prepared in two consecutive thermal treatment steps: carbonization and thermal oxidation. In the first step, the four different biomasses were carbonized in $\mathrm{N}_{2}$ atmosphere at $800{ }^{\circ} \mathrm{C}$ for 2 hours with a heating rate of $5{ }^{\circ} \mathrm{C} \min ^{-1}$. The carbonized products are named as $\mathrm{X}-800(\mathrm{X}=\mathrm{S}, \mathrm{M}, \mathrm{B}$ and $\mathrm{C})$, where the $\mathrm{S}, \mathrm{M}, \mathrm{B}$ and $\mathrm{C}$ are abbreviation of SPF, maple, bamboo and cotton, respectively. Then the carbonized biomasses were further oxidized in air at different temperatures $\left(300-370{ }^{\circ} \mathrm{C}\right)$ for different times (1-7 hours), and the products were named as $\mathrm{X}$-temp-time, where $\mathrm{X}$ is the abbreviation of biomass species, temp and time are the oxidation temperature and time used during the process. For example, M340-5 indicates carbon obtained from maple by oxidizing M-800 at $340{ }^{\circ} \mathrm{C}$ for 5 hours. All samples were grinded into fine particles with diameter between 10-50 $\mu \mathrm{m}$ for the adsorption test, the morphology of grinded particles is provided in Figure S1.

\subsection{Adsorption isotherms}

For adsorption isotherm, $10 \mathrm{~mL} \mathrm{MB}$ aqueous solutions with different initial concentrations were mixed with $1.0 \mathrm{~g} / \mathrm{L}$ porous carbon adsorbent. The pore size dependent adsorption study is performed in neutral solution without adjusting $\mathrm{pH}$ values. To investigate the adsorption capacity at different $\mathrm{pH}$ conditions, the solution $\mathrm{pH}$ was adjusted by $\mathrm{HCl}$ or $\mathrm{NaOH}$ from 1 to 12 . The mixture was magnetically stirred at $25{ }^{\circ} \mathrm{C}$ for 12 hours to ensure equilibrium has been reached. After that, the mixture was separated by filtration and the remaining MB solution was collect for analysis. A linear standard curve relating the UV-Vis adsorption peak intensity at $665 \mathrm{~nm}$ and $\mathrm{MB}$ concentration was constructed, refer to our previous work (Chen et al., 2015a; Chen et al., 2016). Based on this standard curve, the concentration of MB solution after adsorption test can be easily determined by measuring UV-Vis peak intensity at $665 \mathrm{~nm}$. 


\subsection{Characterization}

Microstructure of carbonized and oxidized materials was characterized by scanning electron microscopy (SEM, JEOL-7401), the atomic percentage of oxygen in porous carbon was obtained by Energy Dispersive X-ray Spectroscopy. $\mathrm{N}_{2}$ adsorption-desorption isotherm was performed at $-196{ }^{\circ} \mathrm{C}$ and $\mathrm{CO}_{2}$ adsorption was performed at $0{ }^{\circ} \mathrm{C}$ on a surface analyzer (Micromeritics Tristar II 3020). Before test, samples were degassed at $100{ }^{\circ} \mathrm{C}$ for 12 hours using a Micromeritics FlowPrep 060 degas system. Specific surface area (SSA) was calculated by using two different methods. One is Brunauer-Emmet-Teller (BET) method, where SSA is calculated from $\mathrm{N}_{2}$ adsorption-desorption isotherm. The other is nonlocal density function theory (NLDFT), where the SSA is calculated from combined $\mathrm{N}_{2}$ and $\mathrm{CO}_{2}$ adsorption data by using a slit pore model that is provided by MicroActive Software (Version 4.00). SSA obtained from these two different methods were named as BET-SSA and DFT-SSA, respectively. Zeta potential of porous carbon was measured by Nano-ZS90 (Malvern) in the $\mathrm{pH}$ range of 1-12. Size of MB cation was measured as $1.40 \times 0.60 \times 0.18 \mathrm{~nm}(\mathrm{x} \times \mathrm{y} \times \mathrm{z})$ by using Chem3D software. The energy of MB cation was minimized by MM2 force field method (Allinger, 1977) to ensure it's in most stable state. UV-Vis spectra of MB solution were characterized by a UV-1800 Shimadzu spectrophotometer.

\section{Results and discussion}

\subsection{Microstructure of biomass}

Natural wood, the most abundant renewable resources on planet, can be roughly categorized into softwood and hardwood depending on their internal structure. Softwood is composed of vertical hollow cells. These open cells serve as both supportive structure and conduction channels for transporting water and nutrients (Shafizadeh, 1984). As an example of 
softwood, the morphology of carbonized SPF is shown in Figure 1(a). These cells are closed in hardwood, sparsely distributed larger pores serve as vessels to conduct water and nutrients from the roots (Shafizadeh, 1984). As an example, morphology of carbonized maple is shown in Figure 1(b). Bamboo belongs to grass family, which is composed of fibers those exhibiting a hexagonal or pentagonal shape (Zhang et al., 2015), Figure 1(c). Also, it can be seen that the distribution of the fibers is not uniform. The cell walls in wood and bamboo are all composed of cellulose framework, lignin and hemicellulose. Cellulose exists as fibril aggregates with elliptical spaces in between, lignin fills in the elliptical spaces and hemicellulose acts as binder between cellulose and lignin (Salmen et al., 2012). Cotton is composed of majorly cellulose (>90\%), water $(\sim 8 \%)$ and some other minor species (Zhu et al., 2014). It shows hollow structure with fiber diameter of 10-20 $\mu \mathrm{m}$, Figure 1(d). The inherent macropores in these biomass resources will be very beneficial for fast diffusion of pollutant molecules into the macroporous cell walls.

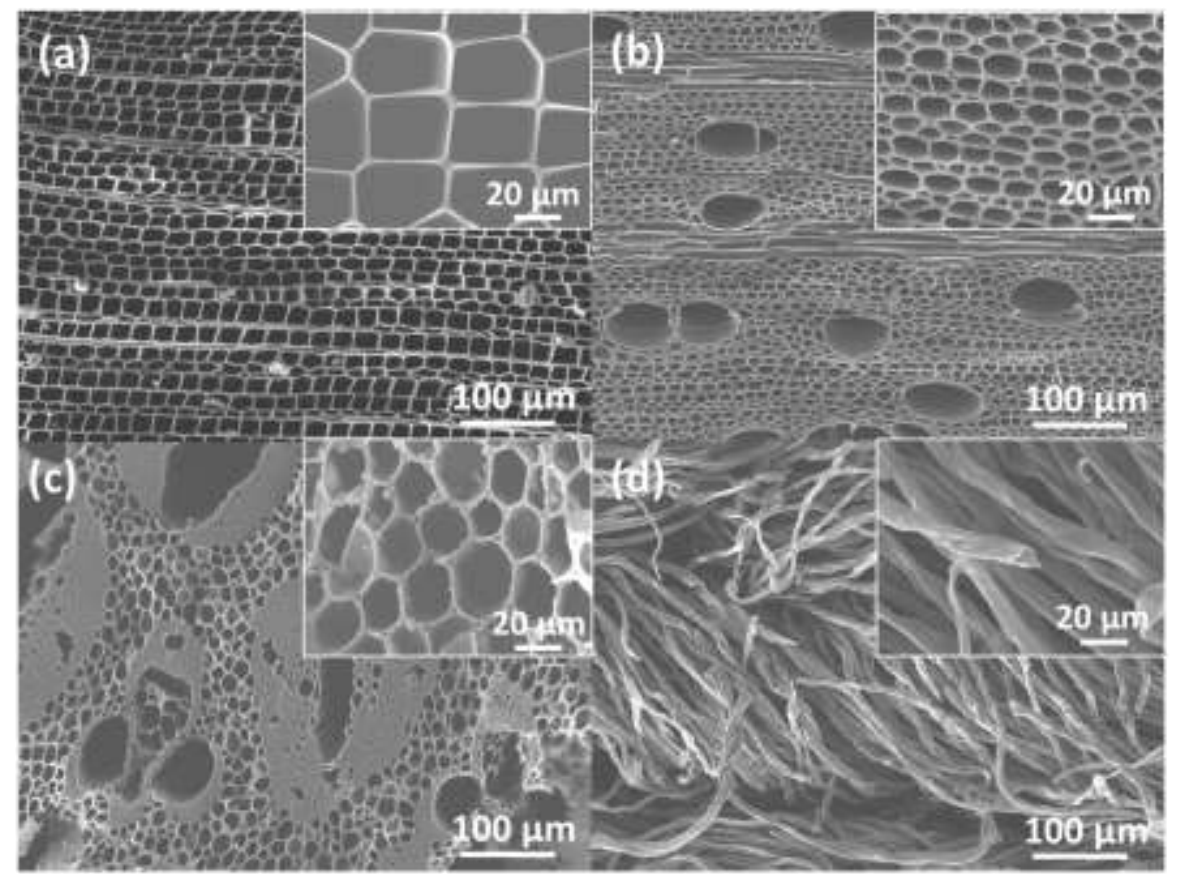

Figure 1. Cross-sectional microstructure of (a) S-800, (b) M-800, (c) B-800 and (d) C-800, insets are magnified SEM images. 
The microstructure of maple oxidized at different temperatures is characterized by SEM. The top view of the cross-section shows well-organized macroporous cell walls in Figure 2. It is obvious that the change of pore structure experienced two distinct stages. At low oxidation temperature of 320 and $340{ }^{\circ} \mathrm{C}$, well-distributed nanoparticles appeared on the surface; at high temperature of 350 and $360{ }^{\circ} \mathrm{C}$, these nanoparticles gradually disappeared from the surface and a porous texture was formed. These spherical particles on the surface have a diameter of about 100 $\mathrm{nm}$, and individual grooves were observed beneath these particles in M-340-5. In M-350-5, all nanoparticles disappeared. The individual grooves started to merge together (Figure 2c) and eventually formed a particle-chain structure with significant amounts of void spaces (Figure 2d). The migrated nanoparticles are carbonized lignin and similar phenomena was observed in SPF (Chen et al., 2015b).

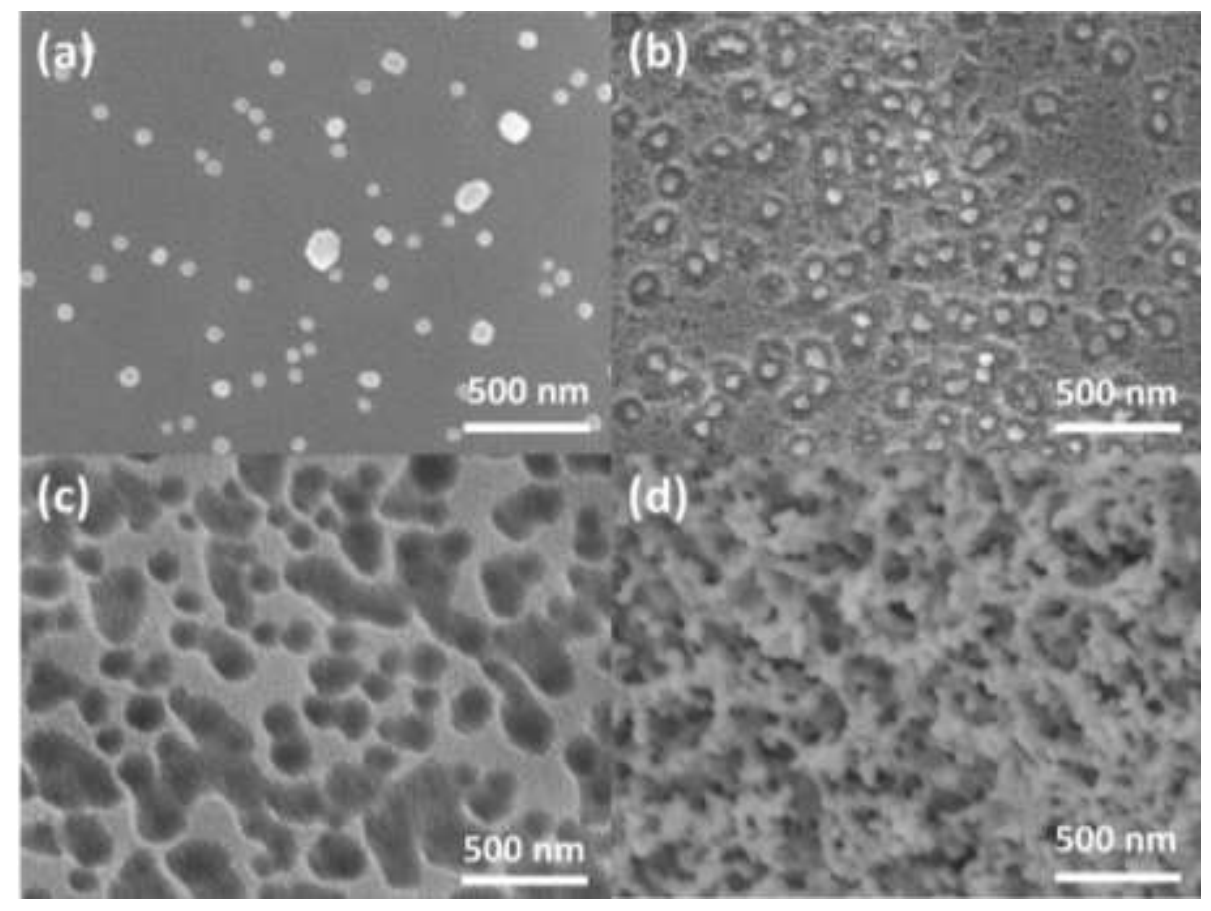

Figure 2. SEM microstructures of (a) M-320-5, (b) M-340-5, (c) M-350-5 and (d) M-360-5. 
Different phenomenon was observed during thermal oxidation on carbonized bamboo. At low temperature, pit appeared on the bamboo surface and the pit size increased with increasing oxidation temperature, Figure 3. An interpenetrating framework was formed when increasing oxidation temperature to $360{ }^{\circ} \mathrm{C}$, Figure 3(d). Unlike the nanoparticle migrationdegradation processes in wood, the pits in bamboo are generated directly. It's also worth mentioning that the size of pores in bamboo is much smaller than those in maple.

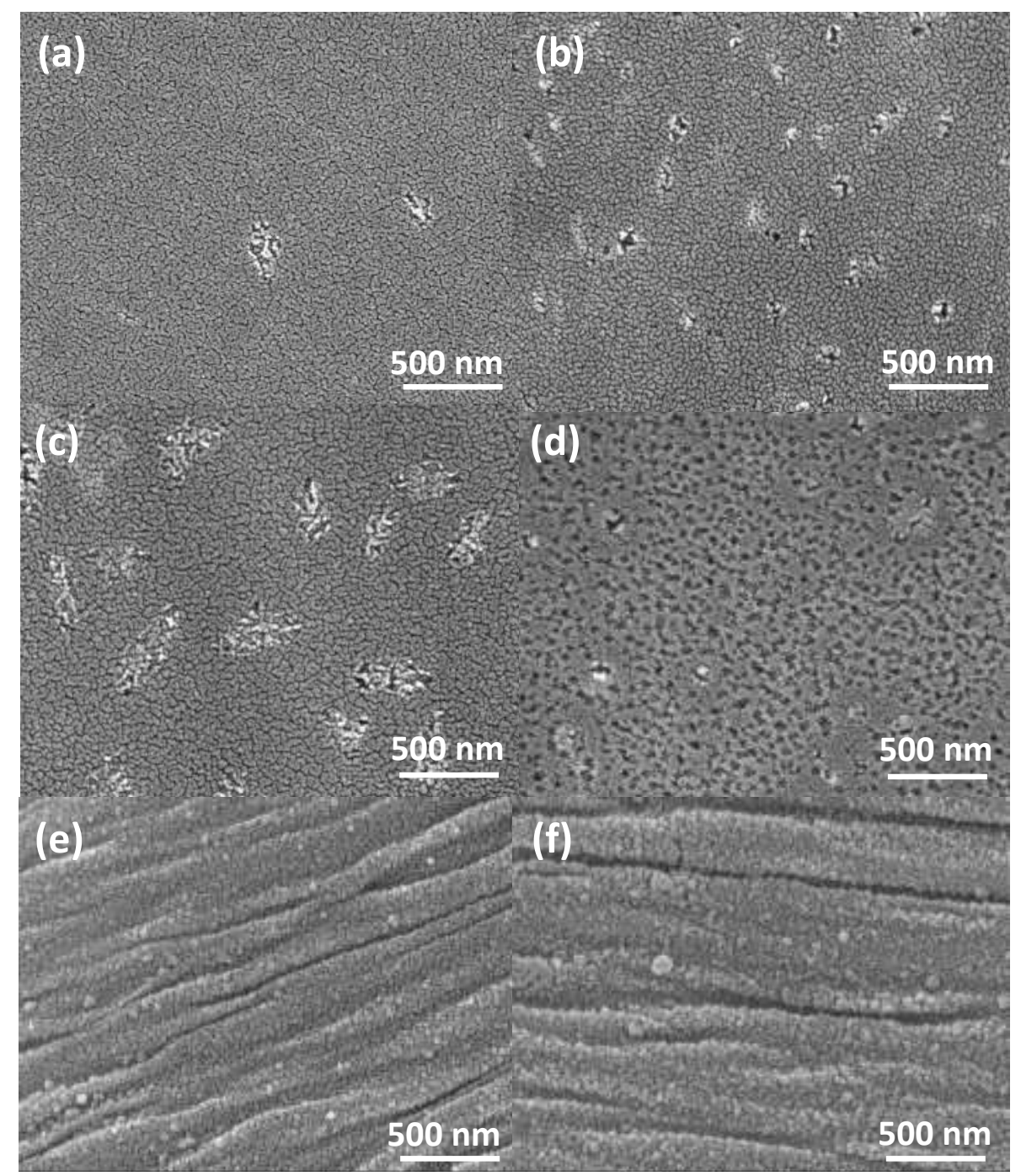

Figure 3. SEM microstructures of (a) B-320-5, (b) B-340-5, (c) B-350-5, (d) B-360-5, (e) C$320-5$ and (f) C-350-5. 
For oxidized cotton shown in Figure 3 (e\&f), the sample surface became much rougher with well-distributed particles on surface, but no obvious pores were observed. As discussed above, those visible pores in maple and bamboo originate from the degradation of lignin phase. Since lignin is not existed in cotton, visible pores are not expected in the oxidized cotton.

\subsection{Pore structure}

To better understand the pore structure evolution during the thermal oxidation process, $\mathrm{N}_{2}$ adsorption-desorption isotherm and $\mathrm{CO}_{2}$ adsorption were performed. All X-800 (X=S, M, B and C) samples show typical Type I isotherm with significant adsorption in low pressure region and negligible adsorption in high pressure region, Figure 4(a-d). Type I isotherm indicates a typical microporous structure with pore diameter smaller than $2 \mathrm{~nm}$ (Chen et al., 2005). After thermal oxidation, the quantity of adsorbed $\mathrm{N}_{2}$ increased significantly at low relative pressure, which indicated the increased microporous surface area. Moreover, hysteresis loops were observed in oxidized samples confirming the formation of mesopores (Chen et al., 2015c). In general, thermal oxidation increased both the mesoporous and microporous surface area. It's worth mentioning that some samples, such as B-320-5, C-320-5 and C-340-5, still show Type I isotherm, which means the low oxidation temperature was not able to change the pore structure for these samples.

The DFT-SSA distribution was shown in Figure 4(e-h). In general, the SSA increased with increasing oxidation temperature. It is obvious that the increased surface area after

oxidation was contributed from both micropores $(<2.0 \mathrm{~nm})$ and mesopores $(2-50 \mathrm{~nm})$. For example, S-800 shows increased surface area at $\sim 1.0 \mathrm{~nm}$ after oxidation at relatively lower temperatures of $330-350{ }^{\circ} \mathrm{C}$, clearly indicating the contribution from newly generated micropores. Besides, the surface area keeps increasing within the 2-50 nm region, which further confirmed 
the contribution of mesopores to surface area. Compared to S-800, the surface area at $\sim 1.0 \mathrm{~nm}$ region decreases when oxidized at higher temperatures of 360 and $370{ }^{\circ} \mathrm{C}$ and then increases in the larger pore size region. These results provide solid evidence on the pore evolution process during thermal oxidation. Specifically, the oxygen in air will firstly react with and degrade less thermally stable carbons, leading to the generation of micropores at lower oxidation temperature. Further increasing oxidation temperature lead to the propagation of these micropores into mesopores. For other three oxidized biomass materials, the increased surface area is also contributed from both micropores and mesopores. However, it is worth mentioning that the increase of surface area in the mesopore region is not distinguishable for bamboo and cotton. Recall the structure of these four biomass resources, SPF and maple are composed of cellulose framework and lignin domains. After removing the lignin phase by thermal oxidation, pores with dimension similar to lignin domains will be generated. While for bamboo, the lignin domain is much smaller than that of two wood resources, as confirmed by SEM, which well explains the less surface area contribution from larger pores. Cotton is typically composed of more than $90 \%$ cellulose without lignin. Therefore, significant structural change and apparent pore evolution would not be expected during oxidation. 

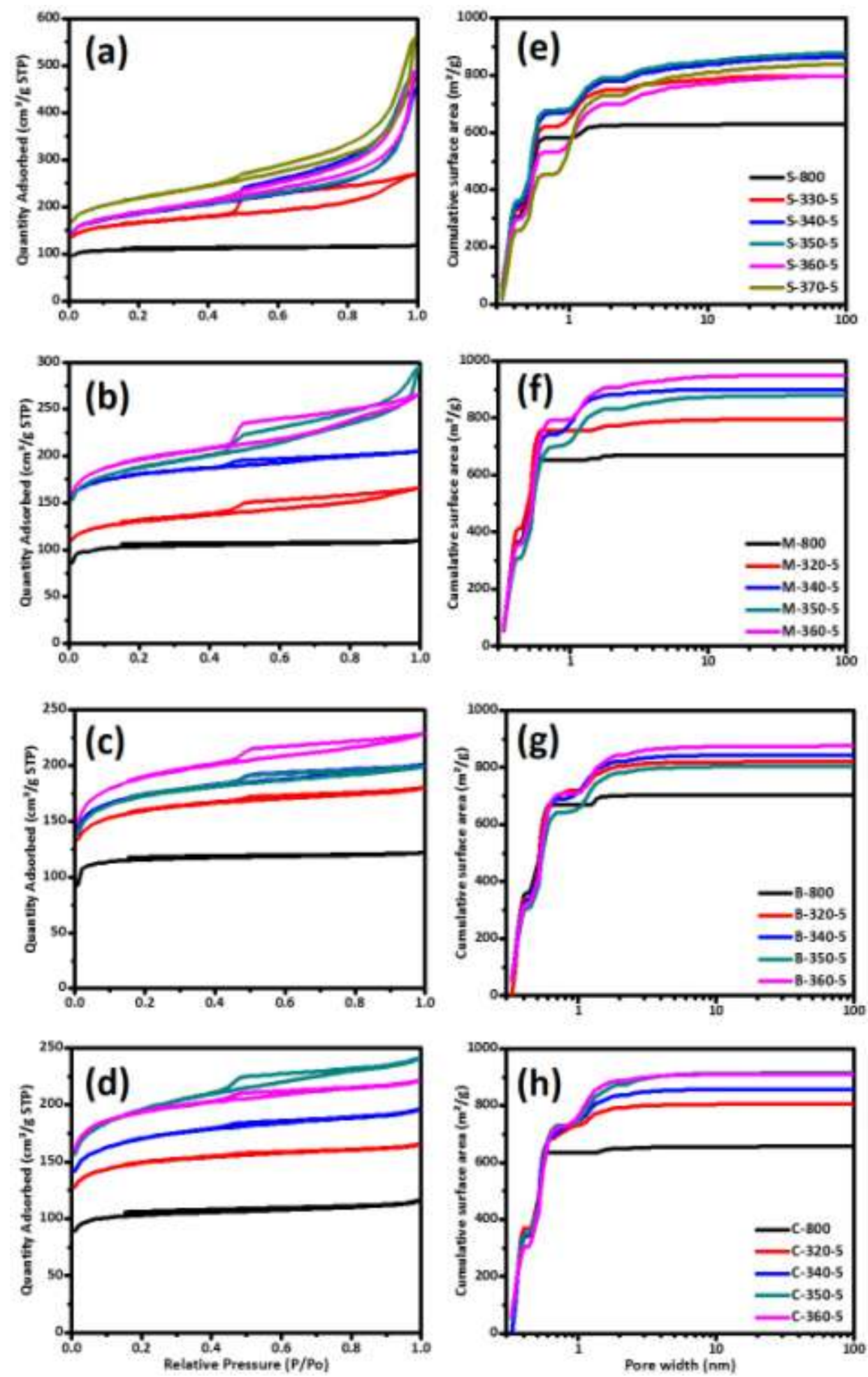

Figure 4. $\mathrm{N}_{2}$ adsorption-desorption isotherm and DFT pore size distribution of porous carbon after oxidation at different temperatures. (a\&e) SPF, (b\&f) maple, (c\&g) bamboo (d\&h) cotton. 
Table 1. Summarized BET results of porous carbon adsorbent.

\begin{tabular}{|c|c|c|c|c|c|c|}
\hline & $\begin{array}{c}\text { BET-SSA } \\
\left(\mathrm{m}^{2} / \mathrm{g}\right)\end{array}$ & $\begin{array}{c}\text { DFT-SSA } \\
\left(\mathrm{m}^{2} / \mathrm{g}\right)\end{array}$ & $\begin{array}{c}\text { E-SSA } \\
\left(\mathrm{m}^{2} / \mathrm{g}\right)\end{array}$ & $\begin{array}{c}\text { PD } \\
(\mathbf{n m})\end{array}$ & $\begin{array}{c}\text { PV } \\
\left(\mathrm{cm}^{3} / \mathrm{g}\right)\end{array}$ & $\underset{(\mathrm{mg} / \mathrm{g})}{\mathbf{q}_{\max }}$ \\
\hline S-800 & 421 & 628 & 10 & 3.2 & 0.02 & 8 \\
\hline S-330-5 & 623 & 796 & 67 & 4.5 & 0.16 & 113 \\
\hline S-340-5 & 686 & 862 & 111 & 4.5 & 0.24 & 210 \\
\hline S-350-5 & 694 & 875 & 111 & 4.5 & 0.24 & 223 \\
\hline S-360-5 & 693 & 797 & 124 & 4.5 & 0.28 & 222 \\
\hline S-370-5 & 805 & 837 & 134 & 4.5 & 0.31 & 254 \\
\hline M-800 & 401 & 670 & 12 & 3.0 & 0.02 & 8 \\
\hline M-320-5 & 493 & 796 & 40 & 3.8 & 0.07 & 31 \\
\hline M-340-5 & 686 & 899 & 36 & 3.3 & 0.07 & 100 \\
\hline M-350-5 & 706 & 879 & 69 & 4.1 & 0.15 & 198 \\
\hline M-360-5 & 740 & 949 & 69 & 4.1 & 0.14 & 233 \\
\hline B-800 & 447 & 703 & 8 & 2.9 & 0.02 & 10 \\
\hline B-320-5 & 606 & 819 & 40 & 2.9 & 0.06 & 96 \\
\hline B-340-5 & 659 & 843 & 46 & 3.1 & 0.07 & 31 \\
\hline B-350-5 & 655 & 803 & 52 & 3.0 & 0.07 & 150 \\
\hline B-360-5 & 713 & 875 & 68 & 3.2 & 0.10 & 209 \\
\hline C-800 & 381 & 656 & 17 & 1.8 & 0.03 & 9 \\
\hline C-320-5 & 566 & 805 & 30 & 2.9 & 0.05 & 41 \\
\hline C-340-5 & 642 & 857 & 45 & 2.9 & 0.07 & 111 \\
\hline C-350-5 & 730 & 914 & 74 & 3.1 & 0.12 & 219 \\
\hline C-360-5 & 735 & 909 & 46 & 3.1 & 0.08 & 242 \\
\hline S-350-1 & 557 & 761 & 41 & 4.1 & 0.09 & 66 \\
\hline S-350-3 & 633 & 790 & 80 & 4.4 & 0.18 & 146 \\
\hline S-350-7 & 725 & 784 & 129 & 4.6 & 0.29 & 269 \\
\hline M-350-1 & 561 & 759 & 25 & 3.5 & 0.05 & 28 \\
\hline M-350-3 & 576 & 795 & 30 & 3.6 & 0.06 & 34 \\
\hline M-350-7 & 890 & 1005 & 81 & 4.1 & 0.18 & 233 \\
\hline B-350-1 & 525 & 765 & 21 & 2.9 & 0.03 & 27 \\
\hline B-350-3 & 654 & 858 & 45 & 3.3 & 0.07 & 129 \\
\hline B-350-7 & 713 & 856 & 64 & 3.1 & 0.09 & 189 \\
\hline
\end{tabular}

The BET specific surface area (BET-SSA), DFT specific surface area (DFT-SSA), effective specific surface area (E-SSA), average pore diameter (PD), pore volume (PV) and maximum adsorption capacity $\left(\mathrm{q}_{\max }\right)$ are summarized in Table 1 . The BET-SSA for all the 
carbonized samples X-800 ranges from 380 to $450 \mathrm{~m}^{2} / \mathrm{g}$. After thermal oxidation, BET-SSA increased gradually with increasing oxidization temperature and reached up to around $890 \mathrm{~m}^{2} / \mathrm{g}$. Although specific surface area calculated from NLDFT method show some deviation from the one calculated from BET method, it gives a similar trend that DFT-SSA increases with increasing oxidation temperature. For the two kinds of wood species, the pore diameter of SPF and maple can reach to 4.5 and $4.1 \mathrm{~nm}$ after oxidation, an increase of 43.2 and $38.4 \%$ respectively, compared to the samples without oxidation process. The pore diameter is relatively smaller, which is 3.2 and $3.1 \mathrm{~nm}$ for bamboo and cotton. These results are reasonable considering their different natural structure and composition.

From above characterizations, it can be concluded that all these four different renewable resources can be processed into porous carbon materials with high surface area through the facile two-step process, carbonization and thermal oxidation, without using any toxic/corrosive chemicals. Depending on the oxidation conditions, BET-SSA can reach up to $890 \mathrm{~m}^{2} / \mathrm{g}$, which is even higher than commercial activated carbon $\left(650 \mathrm{~m}^{2} / \mathrm{g}\right.$ for HDB M-1951, Cabot Corp.). Moreover, the generated micro- and meso-pores during this process together with the intrinsic macropores carried by nature enable a unique hierarchically structured porous carbon material that could be used as a good adsorbent for studying the adsorption behavior.

\subsection{Isothermal adsorption}

To study the size dependent adsorption behavior in these porous carbons, methylene blue (MB) was selected as the probing molecule. The adsorption capacity for MB was measured by isotherm adsorption and the results were then analyzed by Langmuir model, Equation (1) (Langmuir, 1918):

$$
\frac{c_{e}}{q_{e}}=\frac{c_{e}}{q_{\max }}+\frac{1}{q_{\max } k}
$$


where $c_{e}(\mathrm{mg} / \mathrm{L})$ is the dye concentration remained in the solution at equilibrium, $q_{e}(\mathrm{mg} / \mathrm{g})$ is the amount of dye adsorbed onto adsorbent at equilibrium, $q_{\max }(\mathrm{mg} / \mathrm{g})$ is the maximum adsorption capacity and $k$ represents the energy constant related to the energy of adsorption. $q_{e}$ can be calculated by Equation (2):

$$
q_{e}=\frac{c_{0}-c_{e}}{m / V}
$$

where $c_{0}(\mathrm{mg} / \mathrm{L})$ and $c_{e}(\mathrm{mg} / \mathrm{L})$ are initial and equilibrium MB concentrations, $m(\mathrm{~g})$ is the mass of adsorbent and $V(\mathrm{~L})$ is the volume of MB solution. Maximum adsorption capacity $\left(q_{\max }\right)$ can be determined from the slope of the linearly fitted $c_{e} / q_{e} \sim c_{e}$ curve. The adsorption isotherm results can be well fitted with Langmuir model, Figure 5, and the $q_{\max }$ can be calculated and summarized in Table 1. The fitting curves of other materials are shown in Figure S2.
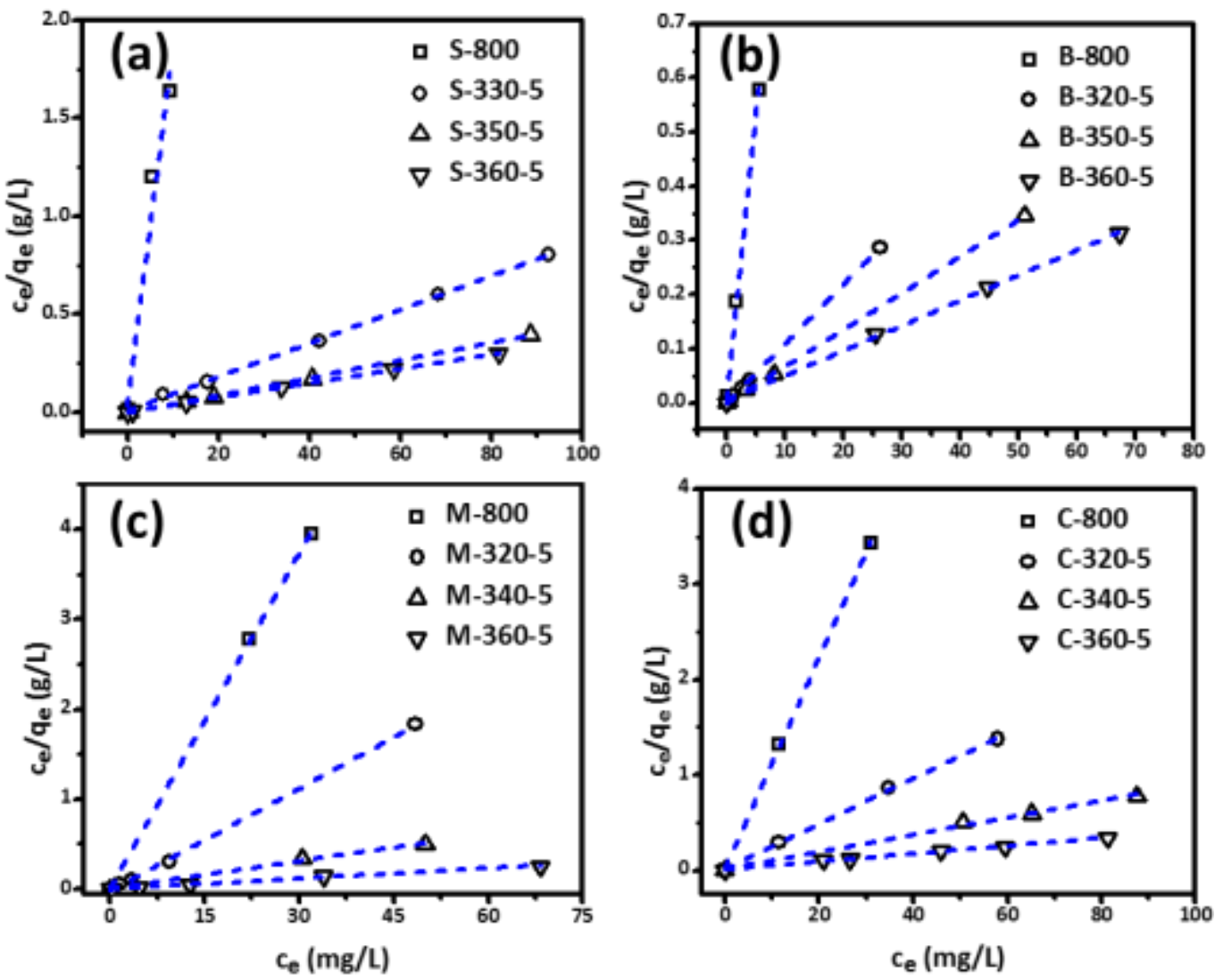

Figure 5. Adsorption isotherm of porous carbon synthesized from (a) SPF, (b) bamboo, (c) maple, and (d) cotton. The dash lines are the linear fitting with Langmuir model. 
As summarized in Table 1 , the $q_{\max }$ of $\mathrm{X}-800$ is only about $10 \mathrm{mg} / \mathrm{g}$. However, it can reach up to $269 \mathrm{mg} / \mathrm{g}$ after the thermal oxidation process, which is comparable to the performance of commercial activated carbon (245 mg/g for HDB M-1951, Cabot Corp.) The thermal oxidation greatly increased the surface area and pore size, which is beneficial to the enhancement of adsorption capacity. Meanwhile, the thermal oxidation introduced more oxygen elements, Figure S3, leading to a more hydrophilic surface that makes the surface more accessible by MB molecule and contributes to the adsorption capacity. The $\mathrm{pH}$ dependent zeta potential and adsorption capacity of various porous carbon materials is shown in Figure S4, where larger adsorption capacity is observed at higher $\mathrm{pH}$ conditions.

\subsection{Pore size dependent adsorption}

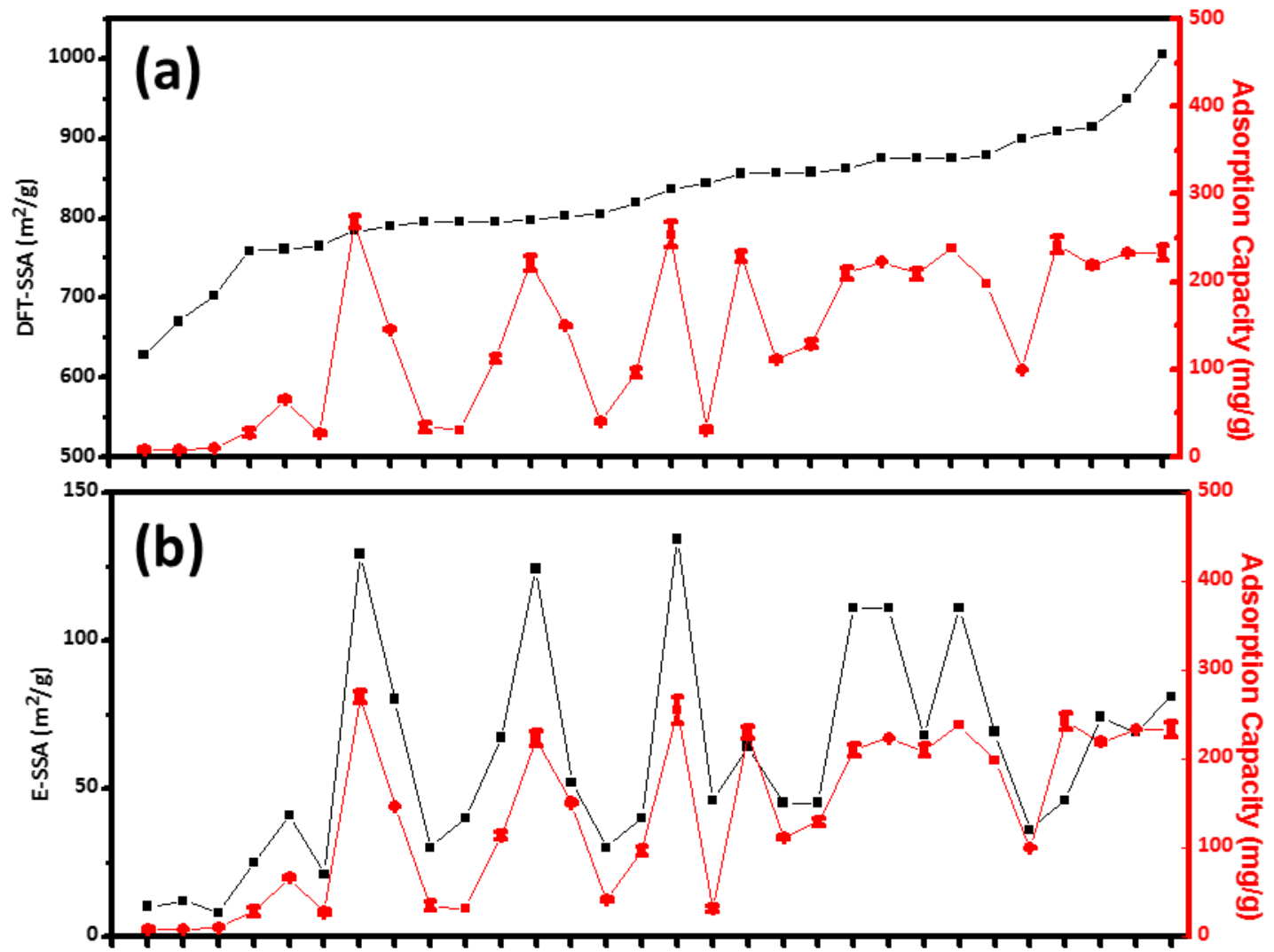

$8887)^{-1}$

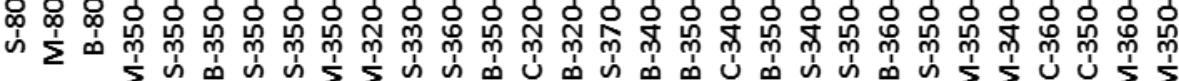

Figure 6. Relationship between adsorption capacity and DFT-SSA and E-SSA. 
To explore the relationship between surface area and adsorption capacity, DFT-SSA and adsorption capacity were plotted in Figure 6(a) and no clear correlation can be found between each other. For example, sample with higher DFT-SSA didn't always show a larger adsorption, which indicates the poor dependence of adsorption capacity on total surface area. Since only the surface area with pore size larger than $\mathrm{MB}$ can be utilized in $\mathrm{MB}$ adsorption, it is more reasonable to consider a relationship between effective surface area and $q_{\max }$.

To get the effective surface area, size of MB cation was calculated as $1.40 \times 0.60 \times$ $0.18 \mathrm{~nm}(\mathrm{x} \times \mathrm{y} \times \mathrm{z})$ by using Chem3D software, Figure S5. Since MB molecule will be dissociated in water and only cation (coloring component) is adsorbed (Cenens and Schoonheydt, 1988), the cation of MB is considered for size estimation in this work. By matching the size of MB cation and pore size of adsorbent, only part of the surface area can be utilized for MB adsorption due to the restricted access by small pores.

Here, effective specific surface area (E-SSA) and ineffective specific surface area (InESSA) are introduced to better represent the relationship between surface area and adsorption capacity. E-SSA is defined as the cumulative DFT-SSA of pores larger than MB cation $(>1.40$ $\mathrm{nm})$, and InE-SSA is the area of pores smaller than MB cation $(<1.40 \mathrm{~nm})$. By separating E-SSA and InE-SSA, the dependence of adsorption capacity on E-SSA can be clearly observed in Figure 6(b). These results demonstrated that only E-SSA was accessible by MB and it determined the adsorption capacity. Simply improve the total surface area of adsorbent does not necessary help to increase the overall adsorption capacity.

The surface area vs. material performance relationship has been studied in in other systems, such as supercapacitors. Shi et. al. (Shi, 1996) attempted to correlate the capacitance with total surface area but failed. Instead, he assumed that the capacitance contribution from 
internal and external surface area is different. Then, a simple model is proposed to correlate capacitance with external and internal surface area. Although Shi's model correlates well with experimental results, the division of capacitance contribution into external and internal surface area at $2.0 \mathrm{~nm}$ is arbitrary and lacks physical meaning. Zhang and coworkers (Zhang et al., 2013) then introduced the concept of effective surface area to correlate the supercapacitor performance. They found that the capacitance of carbon materials was strongly dependent on the effective specific surface area that was accessible to the electrolyte instead of total surface area.

To better understand the effect of E-SSA and InE-SSA on adsorption capacity, a simple mathematical model was proposed to quantify the contribution of adsorption capacity from ESSA and InE-SSA, respectively, as described in Equation (3):

$$
C_{\text {exp }}=C_{i n E} * I n E-S S A+C_{E} * E-S S A
$$

where $C_{\text {exp }}$ is the adsorption capacity of the adsorbent $(\mathrm{mg} / \mathrm{g})$, and is determined from experiment. $C_{i n E}$ and $C_{E}$ are the adsorption capacity contributed from unit InE-SSA $\left(\mathrm{mg} / \mathrm{m}^{2}\right)$ and E-SSA $\left(\mathrm{mg} / \mathrm{m}^{2}\right)$, respectively.

This model is based on two assumptions: (1) the adsorption process follows Langmuir adsorption model and (2) adsorption capacity depends only on InE-SSA and E-SSA. Many other factors may also affect the adsorption property including surface area, pore size distribution and surface chemistry. Surface chemistry will influence the adsorption process in such a way that the surface between adsorbent and adsorbate molecule may interact through covalent bonding (Sagiv, 1980), hydrogen bonding (Misra, 1988), van der Waals force (Van Oss et al., 1986) or electrostatic force (Chen et al., 2016) if functional groups or charges exist. Typically, these interfacial interactions will help to promote the adsorption process and expedite the saturation of monolayer coverage. The influence of electrostatic force depends on the charges on the 
adsorbent/adsorbate surface. If the surfaces of adsorbent and adsorbate are oppositely charged (one positively charged and the other negatively charged), then the electrostatic attraction force will facilitate the adsorption process. If same charge exists on adsorbent and adsorbate, the electrostatic repelling force will cause large deviation of experimental adsorption capacity from theoretical values. In current adsorption system, adsorbent is negatively charged due to the existence of oxygen containing functional groups and $\mathrm{MB}$ cation is positively charged. The electrostatic attraction force dominates the adsorption process and promotes the monolayer adsorption of MB cation onto carbon adsorbent. By fitting the adsorption data to the proposed model, adsorption capacity contributed from unit InE-SSA and E-SSA can be quantified. And it was determined that $C_{i n E}=0.013 \mathrm{mg} / \mathrm{m}^{2}$ and $C_{E}=2.018 \mathrm{mg} / \mathrm{m}^{2}$. It clearly reveals that the adsorption capacity contributed by E-SSA is much larger than InE-SSA, which is about 150 times higher than the later. The slight contribution of InE-SSA $\left(0.013 \mathrm{mg} / \mathrm{m}^{2}\right)$ could be attributed to the small portion of MB cations those diffused into the small pores in a longitudinal molecular configuration. This model can be used to predict the adsorption capacity of other adsorbents by providing E-SSA and InE-SSA inputs. It was further verified by precisely predicting the adsorption capacity with B-320-5 and commercial activated carbon (Cabot-AC), Figure S6.

\subsection{Theoretical calculation}

As is well known, adsorption is a surface based phenomenon and only a monolayer is formed when the adsorption reaches equilibrium based on Langmuir adsorption model. Since the contribution of InE-SSA to overall adsorption capacity is negligible, the theoretical adsorption capacity is calculated by using E-SSA only. Considering the molecule geometry, MB cation can be adsorbed on the adsorbent surface in three different conformations, $x-y, x-z$ and $y-z$, as illustrated in Table 2. $x-y$ and $y-z$ conformations represent the two extreme cases, where lowest 
and highest theoretical adsorption capacities can be obtained, respectively. From all the three cases in Table 2, the theoretical adsorption capacity lies between $1.2 \sim 9.1 \times 10^{18} \mathrm{MB}$ cations $/ \mathrm{m}^{2}$ considering all the three possible adsorption patterns. The fitting results by using Langmuir model gives the adsorption capacity of $2.02 \mathrm{mg} / \mathrm{m}^{2}$, which equals to $4.3 \times 10^{18} \mathrm{MB}$ cations $/ \mathrm{m}^{2}$. The highly consistency between experimental results and theoretical calculation of adsorption capacity further confirms the validity of the model and the assumption of monolayer adsorption of $\mathrm{MB}$ on the porous carbon materials.

Table 2. Theoretical capacity obtained in different adsorption pattern.

\begin{tabular}{|c|c|c|c|c|}
\hline $\begin{array}{l}\text { Case } \\
\text { No. }\end{array}$ & Adsorption pattern & $\begin{array}{l}\text { Dimension } \\
(\mathrm{nm} * \mathrm{~nm})\end{array}$ & $\begin{array}{l}\text { Contact area } \\
\left(\mathrm{nm}^{2}\right)\end{array}$ & $\begin{array}{c}\mathrm{C}_{\text {theory }} \\
\text { (molecules } / \mathrm{m}^{2} \text { ) }\end{array}$ \\
\hline $1^{*}$ & & $1.40 \times 0.60$ & 0.84 & $1.2 \times 10^{18}$ \\
\hline $2^{*}$ & 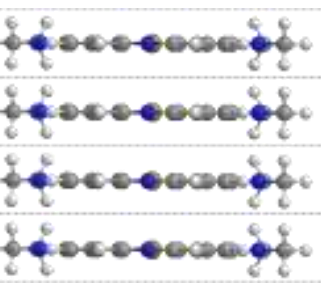 & $1.40 \times 0.18$ & 0.25 & $3.9 \times 10^{18}$ \\
\hline $3 *$ & & $0.60 \times 0.18$ & 0.11 & $9.1 \times 10^{18}$ \\
\hline
\end{tabular}

*Case 1-Adsorption in $\mathrm{x}-\mathrm{y}$ plane, Case 2-Adsorption in the $\mathrm{x}-\mathrm{z}$ plane, Case 3-Adsorption in the $\mathrm{y}$-z plane.

\section{Conclusions}

In summary, hierarchically porous carbon was successfully synthesized from different biomass resources including hardwood, softwood, grass and cotton, via a two-step process 
(carbonization and thermal oxidation). The surface area and pore size can be well controlled by tuning the oxidation temperature and duration. The highest BET surface area can reach up to $890 \mathrm{~m}^{2} / \mathrm{g}$. These porous carbons demonstrate excellent adsorption capacity and size dependent adsorption behavior. Taking the MB size (the largest dimension) as the cutting-off pore size for separating effective and ineffective surface area, the adsorption capacity shows strong correlation with the effective surface area rather than the total surface area. Based on all these prepared porous carbon materials with controlled surface area and tunable pore size, a model relating the adsorption capacity to ineffective and effective specific surface area has been developed and validated by commercial activated carbon. The assumption of monolayer adsorption has also been verified by theoretical calculation. Revealing the pore size dependent adsorption behavior in these biomasses derived porous carbon adsorbents will help to understand the adsorptive behavior of adsorbate in hierarchical porous structures and design more effective materials (either from biomass or other carbon resources) targeting to specific adsorption applications.

\section{Acknowledgements}

Acknowledgement is made to the Donors of the American Chemical Society Petroleum Research Fund (\#55570-DNI10) for support of this research. J.Z acknowledges the support from NSF (CBET-1603264). Partial support from start-up fund and Faculty Research Committee of The University of Akron are also acknowledged.

\section{References}


Acharya, J., Sahu, J.N., Mohanty, C.R., Meikap, B.C., 2009. Removal of lead(II) from wastewater by activated carbon developed from Tamarind wood by zinc chloride activation. Chem. Eng. J. 149, 249-262.

Ahmadpour, A., Do, D.D., 1996. The preparation of active carbons from coal by chemical and physical activation. Carbon 34, 471-479.

Alabadi, A., Razzaque, S., Yang, Y., Chen, S., Tan, B., 2015. Highly porous activated carbon materials from carbonized biomass with high $\mathrm{CO}_{2}$ capturing capacity. Chem. Eng. J. 281, 606612.

Allinger, N.L., 1977. Conformational analysis. 130. MM2. A hydrocarbon force field utilizing V1 and V2 torsional terms. J. Am. Chem. Soc. 99, 8127-8134.

Anoop Krishnan, K., Sreejalekshmi, K.G., Baiju, R.S., 2011. Nickel(II) adsorption onto biomass based activated carbon obtained from sugarcane bagasse pith. Bioresour. Technol. 102, 1023910247.

Babel, S., Kurniawan, T.A., 2004. Cr(VI) removal from synthetic wastewater using coconut shell charcoal and commercial activated carbon modified with oxidizing agents and/or chitosan. Chemosphere 54, 951-967.

Cenens, J., Schoonheydt, R.A., 1988. Visible Spectroscopy of Methylene-Blue on Hectorite, Laponite-B, and Barasym in Aqueous Suspension. Clay Clay Miner. 36, 214-224.

Chen, B.L., Ockwig, N.W., Millward, A.R., Contreras, D.S., Yaghi, O.M., 2005. High $\mathrm{H}_{2}$ adsorption in a microporous metal-organic framework with open metal sites. Angew. Chem. Int. Ed. 44, 4745-4749.

Chen, L., Ji, T., Brisbin, L., Zhu, J.H., 2015a. Hierarchical Porous and High Surface Area Tubular Carbon as Dye Adsorbent and Capacitor Electrode. ACS Appl. Mater. Inter. 7, 1223012237.

Chen, L., Ji, T., Mu, L., Zhu, J., 2017. Cotton fabric derived hierarchically porous carbon and nitrogen doping for sustainable capacitor electrode. Carbon 111, 839-848.

Chen, L., Ji, T., Mu, L.W., Shi, Y.J., Brisbin, L.G., Guo, Z.H., Khan, M.A., Young, D.P., Zhu, J.H., 2016. Facile synthesis of mesoporous carbon nanocomposites from natural biomass for efficient dye adsorption and selective heavy metal removal. RSC Adv. 6, 2259-2269. 
Chen, L., Ji, T., Yuan, R., Mu, L., Brisbin, L., Zhu, J., 2015b. Unveiling Mesopore Evolution in Carbonized Wood: Interfacial Separation, Migration, and Degradation of Lignin Phase. ACS Sustain. Chem. Eng. 3, 2489-2495.

Chen, L., Wang, H.Y., Wei, H.G., Guo, Z.H., Khan, M.A., Young, D.P., Zhu, J.H., 2015c. Carbon monolith with embedded mesopores and nanoparticles as a novel adsorbent for water treatment. RSC Adv. 5, 42540-42547.

Cheng, P., Gao, S., Zang, P., Yang, X., Bai, Y., Xu, H., Liu, Z., Lei, Z., 2015. Hierarchically porous carbon by activation of shiitake mushroom for capacitive energy storage. Carbon 93, 315324.

Chingombe, P., Saha, B., Wakeman, R.J., 2005. Surface modification and characterisation of a coal-based activated carbon. Carbon 43, 3132-3143.

Diao, Y.L., Walawender, W.P., Fan, L.T., 2002. Activated carbons prepared from phosphoric acid activation of grain sorghum. Bioresour. Technol. 81, 45-52.

Dutta, S., Bhaumik, A., Wu, K.C.W., 2014. Hierarchically porous carbon derived from polymers and biomass: effect of interconnected pores on energy applications. Energ Environ. Sci. 7, 35743592.

Hameed, B.H., Din, A.T.M., Ahmad, A.L., 2007. Adsorption of methylene blue onto bamboobased activated carbon: Kinetics and equilibrium studies. J. Hazard. Mater. 141, 819-825.

Hasany, S.M., Ahmad, R., 2006. The potential of cost-effective coconut husk for the removal of toxic metal ions for environmental protection. J Environ. Manage. 81, 286-295.

Ji, T., Chen, L., Mu, L.W., Yuan, R.X., Knoblauch, M., Bao, F.S., Zhu, J.H., 2016. In-situ reduction of $\mathrm{Ag}$ nanoparticles on oxygenated mesoporous carbon fabric: Exceptional catalyst for nitroaromatics reduction. Appl. Catal. B-Environ. 182, 306-315.

Ji, T., Chen, L., Schmitz, M., Bao, F.S., Zhu, J.H., 2015. Hierarchical macrotube/mesopore carbon decorated with mono-dispersed Ag nanoparticles as a highly active catalyst. Green Chem. $17,2515-2523$.

Kurosaki, F., Koyanaka, H., Tsujimoto, M., Imamura, Y., 2008. Shape-controlled multi-porous carbon with hierarchical micro-meso-macro pores synthesized by flash heating of wood biomass. Carbon 46, 850-857. 
Kusakabe, K., Kuroda, T., Morooka, S., 1998. Separation of carbon dioxide from nitrogen using ion-exchanged faujasite-type zeolite membranes formed on porous support tubes. J Membr. Sci $148,13-23$.

Kyriakopoulos, G., Doulia, D., 2006. Adsorption of Pesticides on Carbonaceous and Polymeric Materials from Aqueous Solutions: A Review. Separ. Purif. Rev. 35, 97-191.

Kyriakopoulos, G.L., Arabatzis, G., Chalikias, M., 2016. Renewables exploitation for energy production and biomass use for electricity generation. A multi-parametric literature-based review. AIMS Energy 4, 762-803.

Langmuir, I., 1918. The adsorption of gases on plane surfaces of glass, mica and platinum. J. Am. Chem. Soc. 40, 1361-1403.

Lee, J., Kim, J., Hyeon, T., 2006. Recent Progress in the Synthesis of Porous Carbon Materials. Adv. Mater. 18, 2073-2094.

Lee, J., Yoon, S., Oh, S.M., Shin, C.H., Hyeon, T., 2000. Development of a new mesoporous carbon using an HMS aluminosilicate template. Adv. Mater. 12, 359-362.

Li, Y.-Q., Samad, Y.A., Polychronopoulou, K., Alhassan, S.M., Liao, K., 2014. Carbon Aerogel from Winter Melon for Highly Efficient and Recyclable Oils and Organic Solvents Absorption. ACS Sustain. Chem. Eng. 2, 1492-1497.

Liu, R.L., Wu, D.Q., Feng, X.L., Mullen, K., 2010. Nitrogen-Doped Ordered Mesoporous Graphitic Arrays with High Electrocatalytic Activity for Oxygen Reduction. Angew. Chem. Int. Ed. 49, 2565-2569.

Liu, Z., Chen, L., Zhang, L., Poyraz, S., Guo, Z.H., Zhang, X.Y., Zhu, J.H., 2014. Ultrafast $\mathrm{Cr}(\mathrm{VI})$ removal from polluted water by microwave synthesized iron oxide submicron wires. Chem Commun. 50, 8036-8039.

Lv, Y., Gan, L., Liu, M., Xiong, W., Xu, Z., Zhu, D., Wright, D.S., 2012. A self-template synthesis of hierarchical porous carbon foams based on banana peel for supercapacitor electrodes. J. Power Sources 209, 152-157.

Malik, P.K., 2003. Use of activated carbons prepared from sawdust and rice-husk for adsorption of acid dyes: a case study of Acid Yellow 36. Dyes Pigm. 56, 239-249.

Meng, L., Zhang, X., Tang, Y., Su, K., Kong, J., 2015. Hierarchically porous silicon-carbonnitrogen hybrid materials towards highly efficient and selective adsorption of organic dyes. Sci. Rep. 5, 7910. 
Misra, D.N., 1988. Adsorption on hydroxyapatite: role of hydrogen bonding and interphase coupling. Langmuir 4, 953-958.

Nakanishi, K., Tanaka, N., 2007. Sol-Gel with Phase Separation. Hierarchically Porous Materials Optimized for High-Performance Liquid Chromatography Separations. Acc. Chem. Res. 40, 863-873.

Qiang, Z., Zhang, L.H., Stein, G.E., Cavicchi, K.A., Vogt, B.D., 2014. Unidirectional Alignment of Block Copolymer Films Induced by Expansion of a Permeable Elastomer during Solvent Vapor Annealing. Macromolecules 47, 1109-1116.

Rodríguez-Reinoso, F., Molina-Sabio, M., 1992. Activated carbons from lignocellulosic materials by chemical and/or physical activation: an overview. Carbon 30, 1111-1118.

Sagiv, J., 1980. Organized monolayers by adsorption. 1. Formation and structure of oleophobic mixed monolayers on solid surfaces. J. Am. Chem. Soc. 102, 92-98.

Salmen, L., Olsson, A.M., Stevanic, J.S., Simonovic, J., Radotic, K., 2012. Structural Organisation of the Wood Polymers in the Wood Fibre Structure. Bioresources 7, 521-532.

Shafizadeh, F., 1984. The Chemistry of Pyrolysis and Combustion. Adv. Chem. Ser., 491-529.

Shi, H., 1996. Activated carbons and double layer capacitance. Electrochim. Acta. 41, 1633-1639. Sing, K.S.W., 1982. Reporting Physisorption Data for Gas Solid Systems-with Special Reference to the Determination of Surface-Area and Porosity. Pure Appl. Chem. 54, 2201-2218.

Tang, J., Liu, J., Li, C., Li, Y., Tade, M.O., Dai, S., Yamauchi, Y., 2015. Synthesis of NitrogenDoped Mesoporous Carbon Spheres with Extra-Large Pores through Assembly of Diblock Copolymer Micelles. Angew. Chem. Int. Ed. 54, 588-593.

Tsai, W.T., Chang, C.Y., Lee, S.L., 1998. A low cost adsorbent from agricultural waste corn cob by zinc chloride activation. Bioresour. Technol. 64, 211-217.

Van Oss, C.J., Good, R.J., Chaudhury, M.K., 1986. The role of van der Waals forces and hydrogen bonds in "hydrophobic interactions" between biopolymers and low energy surfaces. J Colloid Interf. Sci. 111, 378-390.

Wan, D., Li, W.B., Wang, G.H., Chen, K., Lu, L.L., Hu, Q., 2015. Adsorption and heterogeneous degradation of rhodamine B on the surface of magnetic bentonite material. Appl. Surf. Sci. 349, 988-996.

Wang, T.H., Tan, S.X., Liang, C.H., 2009. Preparation and characterization of activated carbon from wood via microwave-induced $\mathrm{ZnCl}_{2}$ activation. Carbon 47, 1880-1883. 
Williams, P.T., Reed, A.R., 2006. Development of activated carbon pore structure via physical and chemical activation of biomass fibre waste. Biomass Bioenergy 30, 144-152.

Zare, K., Gupta, V.K., Moradi, O., Makhlouf, A.S.H., Sillanpää, M., Nadagouda, M.N., Sadegh, H., Shahryari-ghoshekandi, R., Pal, A., Wang, Z.-j., Tyagi, I., Kazemi, M., 2015. A comparative study on the basis of adsorption capacity between CNTs and activated carbon as adsorbents for removal of noxious synthetic dyes: a review. J. Nanostructure Chem. 5, 227-236.

Zhang, L., Yang, X., Zhang, F., Long, G.K., Zhang, T.F., Leng, K., Zhang, Y.W., Huang, Y., Ma, Y.F., Zhang, M.T., Chen, Y.S., 2013. Controlling the Effective Surface Area and Pore Size Distribution of $\mathrm{sp}^{2}$ Carbon Materials and Their Impact on the Capacitance Performance of These Materials. J. Am. Chem. Soc. 135, 5921-5929.

Zhang, X.P., Wang, F., Keer, L.M., 2015. Influence of Surface Modification on the Microstructure and Thermo-Mechanical Properties of Bamboo Fibers. Materials 8, 6597-6608.

Zhao, W., Tang, Y., Xi, J., Kong, J., 2015. Functionalized graphene sheets with poly(ionic liquid)s and high adsorption capacity of anionic dyes. Appl. Surf. Sci. 326, 276-284.

Zhu, J.H., Gu, H.B., Guo, J., Chen, M.J., Wei, H.G., Luo, Z.P., Colorado, H.A., Yerra, N., Ding, D., Ho, T.C., Haldolaarachchige, N., Hopper, J., Young, D.P., Guo, Z.H., Wei, S.Y., 2014. Mesoporous magnetic carbon nanocomposite fabrics for highly efficient $\mathrm{Cr}(\mathrm{VI})$ removal. J Mater. Chem. A 2, 2256-2265. 
Graphical Abstract for

\section{Pore Size Dependent Molecular Adsorption of Cationic Dye in Biomass Derived Hierarchically Porous Carbon}

Long Chen, Tuo Ji, Liwen Mu and Jiahua Zhu*

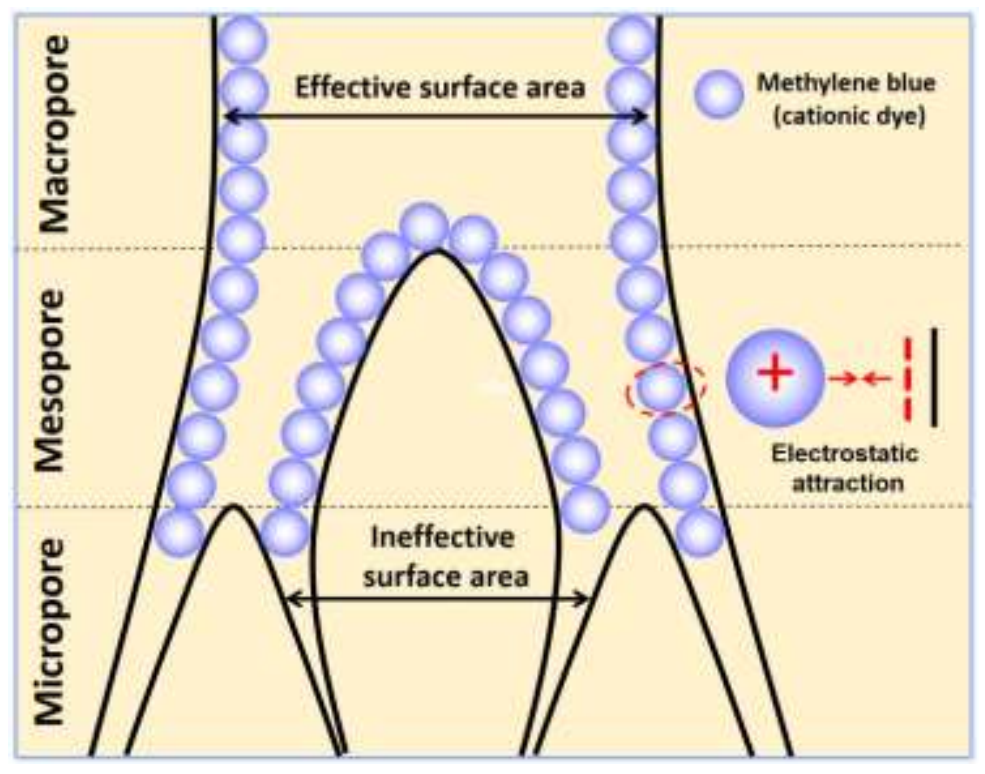

